\title{
Acerca de lo que se dice, se escribe, se narra... Una aproximación a zonas discursivas sobre la autoridad docente en la Universidad contemporánea
}

\author{
María Paula Pierella \\ (Escuela de Ciencias de la Educación) \\ (Universidad Nacional de Rosario. Argentina) \\ (CONICET)
}

\section{Resumen}

En este trabajo proponemos indagar algunas zonas presentes en el "discurso social" (Angenot, 1989) sobre la Universidad, centrándonos en la cuestión de la autoridad.

Nuestra intención es presentar los sentidos atribuidos a la Universidad y, en especial, a los profesores universitarios como objeto de análisis, de intervención política y de opinión, pero también las narrativas de la experiencia desplegadas por estudiantes universitarios próximos a egresar de sus carreras de grado en entrevistas en profundidad y en foros de discusión.

A partir de los aportes de Angenot como guía intentaremos resaltar tendencias generales acerca de aquello que se dice, se escribe, se narra y argumenta sobre la autoridad en la Universidad, haciendo foco en una institución particular: la Universidad Nacional de Rosario. Nos interesa dar cuenta de ciertas tendencias o regularidades discursivas, como así también destacar aquellas zonas que marcan puntos de disidencia con el discurso hegemónico.

\section{Palabras clave:}

Universidad Nacional de Rosario - Autoridad - Discurso social - Profesores - Estudiantes.

\section{Summary}

In this work, we propose to make inquiries about some areas found in the "social discourse" (Angenot, 1989) related to the University focusing on the authority matter.

We intend to present the senses attributed to the University and specially to the professors as subjects of analysis of political intervention and opinion, as well as to the narratives about the experiences displayed in profound interviews and 
discussion meetings by the students who are about to obtain their university degree. We are interested in explaining certain tendencies or discourse regularities as well as emphasizing those areas which express dissent with the hegemonic discourse.

\section{Key words}

National University of Rosario - Authority - Social discourse - Professor - Students.

\section{Introducción}

En tiempos en que se conmemoran acontecimientos centrales en la historia universitaria -la Reforma de 1918, el Movimiento del Mayo Francés de 1968, el Cordobazo, el Rosariazo- y en que se discuten los lineamientos de una nueva ley de educación superior, la Universidad y sus problemáticas actuales adquieren un grado de visibilidad que trasciende las fronteras de las altas casas de estudio para ocupar espacios en la discursividad social del presente.

En este trabajo, que constituye un avance de un proyecto de investigación en curso (1), afirmamos la necesidad de establecer una mirada que, en el proceso de abordar la "cuestión universitaria," considere diversas zonas discursivas, como así también un componente o un registro poco explorado: el de la experiencia. Se habla mucho de lo que la universidad "hoy ya no produce", pero poco sobre lo que allí de todos modos ocurre.

Nuestra intención es entonces presentar los sentidos atribuidos a la Universidad y, en especial, a los profesores universitarios como objeto de análisis, pero también las narrativas de la experiencia desplegadas por estudiantes universitarios próximos a egresar de sus carreras de grado en entrevistas en profundidad y en foros de discusión.

Consideramos que la teoría del discurso social de Marc Angenot constituye un aporte valioso, en tanto nos permite identificar maneras de conocer y de significar lo conocido propias de una sociedad en un momento determinado (Dalmasso, 1999). El "discurso social" es definido por este autor como "todo lo que se dice y se escribe en un estado de sociedad; todo lo que se imprime, todo lo que se habla públicamente o se representa hoy en los medios electrónicos. Todo lo que se narra o argumenta, si entendemos que narrar y argumentar son los dos grandes modos de puesta en discurso.

O más bien llamemos "discurso social" no todo lo empírico, cacofónico a la vez y redundante, sino los sistemas genéricos, los repertorios tópicos, las reglas de encadenamiento de enunciados que en una sociedad dada organizan lo decible, lo narrable y lo opinable y aseguran la división del trabajo discursivo" (Angenot, 1989, p. 13). 


\section{Discursos acerca de la Universidad en la sociedad argentina contemporánea}

Pensar la Universidad en la contemporaneidad desde la perspectiva de Angenot requiere considerar una amplia gama de zonas discursivas incluidas en el discurso social de la época, dando cuenta de las recurrencias y predominios interdiscursivos, hegemónicos en un período dado, de la presencia de "leyes tácitas y de tendencias colectivas en las idiosincrasias de las opiniones individuales" (Angenot, 1998, p. 29).

En su gran mayoría, los discursos actuales acerca de la Universidad argentina, pero con ciertas similitudes en la literatura de la Universidad a nivel mundial, parten de una situación de "crisis": de la institución, de financiamiento, relativas a la masificación y al ingreso irrestricto, de cobertura (2), etc., diagnosticando la necesidad de una reforma radical, pero manifestándose dichos diagnósticos, en no pocas ocasiones, desprovistos del componente de historicidad necesario para analizar fenómenos, ideas y conceptos que dan forma a las cosmovisiones epocales (Carli, 2008) (3), como así también para comprender la crisis institucional de la Universidad enlazada a las respectivas crisis de hegemonía y legitimidad de la misma (De Sousa Santos, 2005 ).

Creemos que esto guarda relación con los modos en que el campo de estudios acerca de la Universidad se fue delineando en la mayoría de los países del globo y en América Latina en particular; más ligados a los desafíos y problemáticas impuestas por decisiones llevadas a cabo desde las esferas políticas nacionales, en estrecha relación con los lineamientos de organismos internacionales, que con intereses académicos de hacer de la Universidad un "objeto" de estudio genuino. Siguiendo a Trow (1996), en este sentido Krotsch y Suasnábar (2002) destacan que la ruptura de la tradicional confianza entre el Estado y la universidad fue condición para la introducción de la evaluación, pero también para la emergencia de los estudios sobre esta última.

Es sabido que la agenda de transformación llevada a cabo por muchos países avanzados en los años 80 emerge en América Latina a fines de esa década, concretándose en los 90 . El discurso que promueven, impulsado fundamentalmente por organismos internacionales como el Banco Mundial, el $B I D$, la UNESCO, incorpora una serie de construcciones léxicas inéditas en el ámbito educativo, vinculadas con el discurso organizacional en general y en especial de las organizaciones de servicios en clave económica. En esos años, no pocos abordajes a modo de diagnóstico de los problemas presentes en los sistemas de educación en general, fueron más allá de la enunciación de la crisis para hacer referencia a figuras más catastróficas. Así, las "ruinas" (Readings, Trindade), las "penumbras" (Gentili) fueron algunas de las metáforas evocadas para dar cuenta de la situación de las Universidades en el mundo (García Guadilla, 2002). Construcciones discursivas que, si bien hacen referencia a una institución en particular, aluden a las fracturas económicas, sociales 
y culturales que impactaron fundamentalmente en la eficacia simbólica de las instituciones surgidas en la modernidad. Precisamente la crisis del 2001 que, como toda crisis actuó como un "revulsivo del imaginario social respecto de la propia identidad" (Tiramonti, 2004, p. 33), ha provocado un quiebre sobre las imágenes de la sociedad de la que formamos parte y de los elementos que constituyen ese imaginario; fundamentalmente la crisis desmiente valoraciones como la igualdad, central en la imagen construida del "ser argentino" y en la dinámica de nuestra vida colectiva (Ibídem).

En esa configuración de la identidad argentina la Universidad pública, tradicional receptora de las clases medias como parte de las estrategias de ascenso social, ocupó un lugar central y es en relación con ese reconocimiento adquirido que las fracturas señaladas impactan con crudeza. Así, un rasgo característico del discurso social del presente es la recurrencia de interpretaciones que nombran de diversas maneras el desajuste epocal o desfase histórico entre la historia del siglo $X X$ y las tendencias emergentes en las últimas décadas del siglo XX y el incipiente siglo XXI (Carli, 2008). Desajuste intrínsecamente vinculado en nuestro país y en el mundo en general con las reformas de la Universidad en el marco de las reformas estatales características de los ' 90 , en tiempos de globalización y transnacionalización de capitales materiales y simbólicos, con consecuencias singulares en las culturas institucionales.

En Argentina, la aprobación en 1995 de la Ley de Educación Superior, corona una serie de medidas dirigidas básicamente a introducir la competitividad y la reforma de las estructuras académicas de la universidad (Krotsch y Suasnábar, 2002), condicionando las prácticas de los actores en ella involucrados y reconfigurando los modos de relación con el Estado, la sociedad y el mercado. La pérdida de confianza del primero respecto de la institución universitaria, manifestada fundamentalmente a través de la exacerbación de los mecanismos de evaluación, rendición de cuentas y control; los discursos de descrédito de la Universidad pública en estrecha relación con el imperio del mercado en la escena social, ponen en evidencia cierto abandono de su "incondicionalidad". La Universidad, como espacio al que se le debería reconocer una "libertad incondicional de cuestionamiento y de proposición, e incluso, más aun si cabe, el derecho de decir públicamente todo lo que exige una investigación, un saber y un pensamiento de la verdad" (Derrida, 2002, pp. 9-10), está de algún modo acorralada; lo cual no implica desconocer la infinidad de estrategias desplegadas para poder evadirse ni la capacidad creativa de los actores singulares.

En el escenario descripto, creemos que la noción de autoridad, en este caso focalizada en la figura de los profesores, merece ser considerada seriamente. 


\section{De la autoridad de los profesores en los discursos referidos a la Universidad. Cuestiones generales}

Un tópico recurrente en las reflexiones sociológicas, culturales, políticas y pedagógicas contemporáneas ha sido el de la crisis de la autoridad y sus consecuencias o efectos en las sociedades y sujetos. Diferentes autores esbozaron hipótesis que intentan explicar la pérdida de sentido de las instituciones sociales cuando las mismas sufren procesos de desautorización y descrédito (Carli, 2001; Narodowski, 1999; Antelo, 2003; Dussel y Caruso, 1999; Caruso, 2001; Duschatsky y Corea, 2002), como así también la profunda crisis de educación como resultante de cambios acelerados producidos en el plano del conocimiento, de la cultura y de la sociedad en su conjunto (Tedesco, 1995; Puiggrós, 1995; Tenti Fanfani, 1994; Carli, 2001, etc.) y el deterioro cultural de la educación (Sarlo, 1998, 2001).

Respecto de la institución universitaria específicamente, entre aquellos marcos teóricos que pueden ser considerados "clásicos" para pensar la vinculación entre autoridad y Universidad, encontramos una fuerte impronta sociológica: la perspectiva de Bourdieu y la de Burton Clark son las más destacadas. El primero, desde una lógica que considera fundamentalmente los condicionantes sociales en el establecimiento de figuras autorizadas, abordando fundamentalmente las luchas por el poder dentro del campo universitario y, el segundo, a partir de diferenciar niveles de autoridad presentes en la institución desde una perspectiva "internista" más cercana a planteos funcionalistas.

Por otro lado, ciertos trabajos orientados a abordar las problemáticas universitarias vinculadas con la emergencia de nuevas configuraciones de relación entre generaciones (De Certeau, 1995), la convivencia intergeneracional de diferentes trayectorias sociales, culturales y formativas de profesores y alumnos (Carli, 2008), el lugar de los profesores como autoridades vinculadas a un saber que puede ser cuestionado (Theodoropoulou, 2001), la necesidad de re-pensar los fundamentos de la universidad pública en una "era sin fundamentos" (Pérez Lindo, 2001), las modificaciones operadas en torno a las expectativas sociales y familiares en relación con la obtención de títulos de educación superior (Mollis, 2001), constituyen puntas que, según nuestro criterio, pueden brindar interesantes aportes al estudio de un tema que es hoy acuciante, en tanto entraña problemáticas profundas vinculadas a las experiencias de formación de los estudiantes universitarios, por un lado, y a la reconfiguración de las identidades docentes, por el otro.

Ahora bien, nos interesa particularmente considerar el modo en que en el discurso social se focalizan las figuras de los profesores universitarios en relación con la noción de autoridad. Nos permitimos arriesgar la hipótesis de que ésta puede ser pensada desde la perspectiva de Angenot como un "ser ideológico", en tanto construcción cuyo proceso de constitución, de contingen- 
cia, de no necesariedad, comienza a ser percibido en el momento en que se presenta como en crisis.

La construcción "crisis de autoridad" como ser ideológico central, a partir del cual es posible dar cuenta de fragmentos del discurso social general, caracteriza en Occidente a los períodos históricos de post guerras o crisis sociales profundas. Un texto clave para abordar esta cuestión lo constituye el capítulo "¿Qué es la autoridad?", incluido en la obra Entre el pasado y el futuro, de Hannah Arendt. Allí, cuando esta pensadora formula dicho interrogante se corrige diciendo que más bien habría que plantearse otra pregunta: ¿qué fue la autoridad? De esta manera, coloca en el pasado una presencia y en el presente la percepción de una carencia que data -según la misma autora- de principios del siglo XX, cuando "(...) la aparición de movimientos políticos destinados a reemplazar el sistema de partidos y el desarrollo de una nueva forma totalitaria de gobierno se produjo con el fondo de una ruptura más o menos general y más o menos dinámica de toda autoridad tradicional" (1996, p. 101). Luego avanza más en su argumento a favor de la crisis de la autoridad diciendo que aquello ausente en el presente no sería la "autoridad en general" sino una forma válida en Occidente durante mucho tiempo; es decir, aquélla que constituyó una amalgama con la tradición y la religión y que, de los tres, la autoridad fue el más estable de los conceptos. Es decir, lo que allí se pondría en cuestión es la autoridad del pasado, de aquello sustentado por la tradición, por las costumbres (4).

Pese a poder señalar esos antecedentes, creemos que lo novedoso en el discurso social del capitalismo de fines del siglo XX y principios del XXI es la inscripción del enunciado de la crisis de autoridad en un trasfondo de "declive del programa institucional" (Dubet, 2006), de pérdida de la "eficacia simbólica" (Zizek, 2001) de instituciones y figuras otrora legítimas, al mismo tiempo que de exaltación de la figura de la autonomía y de primacía del sujeto por sobre las determinaciones de la sociedad. Manifestaciones posibles de ser pensadas, en conjunción con la deslegitimación de lo público como formando parte de una "doxa" (5) que recién en estos últimos años, con el arribo de gobiernos progresistas en la región, comienza a discutirse, generando todo tipo de conflictos y tensiones sociales.

Desde los mensajes publicitarios, los tópicos discursivos del marketing y las lógicas empresariales, la new age, pero también desde ciertas teorías propias del campo de la Sociología o de la Psicología de corte constructivista se impone la figura del individuo como artífice de su propio destino; ocupando durante mucho tiempo la noción de autoridad, principalmente en Argentina a partir del retorno de la democracia, el lugar de "tabú" (6).

Ahora bien, ¿cuáles son los "topos" dentro del discurso universitario por los que transitó esta doxa?, ¿cuál el impacto de la misma sobre la profesión académica? 
Si pensamos a la autoridad del profesor universitario en clave histórica, un elemento -la autonomía- se nos presenta como central en el proceso de su constitución. Pese a que la universidad se asentó en medio de los dos poderes trascendentes que eran el espiritual (Sacerdotum), representado por el Papado, y el temporal (Imperium), encarnado en la persona del Sacro emperador romano; a ellos se agregó la Erudición (Studium) (Leff, 1968, citado en Neave, 2001). Así, el poder divino, el poder sobre la tierra y el poder de la erudición conformaron una especie de autoridad de orden superior sobre una comunidad que no se identificaba por sus fronteras geográficas sino más bien por su unidad religiosa y su integración social en torno de la religiosidad (Ibídem). Con el advenimiento de la Modernidad, el modelo institucional que va a predominar va a estar basado en la Universidad de París, que hace de la autonomía el principio orientador de la profesión académica (Marquina, 2007). "Sobre la base de ese principio, los académicos determinaban el currículo, la admisión de los estudiantes, los grados requeridos, así como el control sobre el gobierno institucional, los recursos de las instituciones y la contratación y promoción del personal. De acuerdo con Altbach (1991) "este concepto de control institucional del cuerpo docente ha permanecido como la piedra fundacional del dogma académico"' (Marquina, 2007, p. 156). Es decir, el modelo de París y no el de Bolonia, en el cual el gremio de estudiantes era el que tenía más poder, fue el que prevaleció en términos generales, desencadenando, fundamentalmente a lo largo del siglo XX luchas estudiantiles por alcanzar y aumentar su nivel de representación en el gobierno de la Universidad.

Los debates en torno al principio del cogobierno, logrado en nuestras tierras con la Reforma de 1918 y vapuleado por la mayoría de las intervenciones militares, prosiguen en la actualidad, fundamentalmente condicionados por el tipo de tratamiento que se le dio en la Ley de Educación Superior $N^{\circ} 24.521$. El artículo 53 inciso "a", en el cual se dictamina: "Que el claustro docente tenga la mayor representación relativa, que no podrá ser inferior al cincuenta por ciento (50\%) de la totalidad de sus miembros"; estaría atentando, de algún modo, contra la dimensión democrática -intramuros- de la Universidad, como así también contra el principio del "demos" reformista, el cual "agrega, a la vocación academicista, el criterio de participación estudiantil, bajo los tres principios siguientes: a) el estudiante ya es un ciudadano pleno y como tal puede y debe hacerse cargo de su responsabilidad en la gestión universitaria; b) la ausencia de participación estudiantil genera endogamia y conformismo docente, produciendo la Universidad de las castas y de los mandarines; c) en una verdadera Universidad todos son estudiantes, incluyendo los profesores, quienes deben formarse en permanencia. Por ende, no existiría un corte drástico entre el estudiante y el docente desde el punto de vista de la ciudadanía universitaria" (Naishtat, 2004, p. 114). 
Esto último es fundamental para pensar la autoridad del profesor universitario. Es decir, a diferencia de la institución escuela, en la cual se configura un vínculo asimétrico entre adultos y niños, en la Universidad el vínculo entre profesores y estudiantes puede ser pensado como simétrico desde un punto de vista generacional, pero asimétrico considerando la relación con el conocimiento y las responsabilidades institucionales diferenciales (Dubet, 2006; Carli, 2008). Mayores niveles de autonomía respecto de otros poderes y mayor simetría en las relaciones pedagógicas constituyen rasgos de identidad que hacen que la autoridad asuma formas diferenciadas. En este sentido, en la institución universitaria cabe pensar la autoridad desde la perspectiva de Gadamer, es decir, fundamentada no en un acto de sumisión y de abdicación de la razón, sino en un acto de reconocimiento y de conocimiento: "conocimiento de que el otro está por encima de uno en juicio y en perspicacia, y de que, en consecuencia, su juicio prevalece o tiene preeminencia sobre el nuestro. Lo que está unido al hecho de que, en verdad, la autoridad no se otorga sino que se adquiere, y debe ser adquirida necesariamente si se quiere apelar a ella" (citado en Ricoeur, 2006, p. 268).

Sin embargo, en la actualidad es posible hablar de ciertos fenómenos de desautorización de los profesores universitarios a nivel global. La modificación de las condiciones laborales, la reducción de fondos, las reformas en los sistemas tradicionales de promoción docente, la introducción de las lógicas de la competencia y la rendición de cuentas, afectaron gradualmente la vida cotidiana de este colectivo (Marquina, 2007). Nociones como las de eficacia, calidad y, sobre todo, eficiencia comienzan a ganar espacio rápidamente en el lenguaje de las autoridades sectoriales y nacionales (7) (Ibídem), aportando, en términos de Angenot, una suerte de "unificación orgánica" y fijando "entrópicamente los límites de lo pensable, de lo argumentable, de lo narrable, de lo escribible" (1998, p. 29).

Fundamentalmente esto es visible a partir de los procesos de evaluación, "fetiche" que se hizo presente de la mano de nociones como las de calidad y eficiencia, condicionando diferentes grados de adaptación a estos discursos y una fuerte filtración de los mismos en el sentido común universitario. García Guadilla destaca en este sentido que dichos procesos de evaluación fueron realizados dentro del formato burocrático, sin una real participación de la comunidad académica y, por sobre todo, con una "falta de protagonismo de los profesores, lo cual se explica, entre otros factores, por las bajas remuneraciones en las instituciones públicas" (2002, p. 89).

Por otro lado, las transformaciones en los modos de acceso al conocimiento, en el sentido del desvanecimiento de las etapas escalonadas de arribo al mismo (Ibídem), la caída de la centralidad del intelectual en el análisis de los problemas sociales en general de la mano del auge del periodismo en el 
tratamiento de todas las temáticas (Follari, 2008), son elementos a considerar para dar cuenta de los cambios producidos en las identidades académicas.

Según Marquina el poder de los académicos fue trasladado, en los ' 80 y ' 90 , hacia el Estado y el mercado, "con nuevas configuraciones para el trabajo académico en las cuales las características más salientes son la burocratización y la mercantilización de lo que debiera ser una tarea autónoma" (2007, p. 145).

En ese marco, la fragmentación y la atomización, las salidas individuales, la exaltación del componente "personal" para argumentar acerca de logros y fracasos está a la orden del día. Pensamos que en tiempos de crisis de ciertas figuras de autoridad que se sostenían en términos institucionales aquello que asume importancia es la acepción de autoridad ligada al "carisma" (8). En términos de Dubet, cuando la autoridad natural ya no apuntala el poder, este último tiene plenas oportunidades de ser reducido a un carisma personal agotador y aleatorio $\mathrm{y}$, como todo trabajo sobre los otros reposa sobre una dimensión de control social, siempre existe el riesgo de poseer demasiado poder, circunstancia percibida como "sadismo", o carecer de él, lo cual es evidencia de debilidad" (Dubet, 2006, p. 427).

\section{Aproximación a visiones acerca de la autoridad en los discursos de los estudiantes}

Aproximarse a la cuestión de la autoridad en la Universidad desde una mirada que tenga en cuenta las experiencias implica asumir la posición de destotalizar, o, utilizando una expresión de Angenot, de "desclausurar" el acercamiento que los discursos académicos, políticos y mediáticos hacen de la institución, siendo concientes también de que el ámbito de los discursos guarda siempre algo del orden de lo inasible.

Pensar la autoridad considerando las voces de los estudiantes, permite acercarnos a particularidades no siempre visibles desde otro tipo de estudios; posibilita hablar no ya de la autoridad, sino de "figuras" de autoridad, figuras "autorizadas" construidas en el discurso. Entendemos la noción de figuras en un sentido barthesiano, es decir, como "retazos del discurso": "Las figuras se recortan según pueda reconocerse, en el discurso que fluye, algo que ha sido leído, escuchado, experimentado. La figura está circunscrita (como un signo) y es memorable (como una imagen o un cuento). Una figura se funda si al menos alguien puede decir: "iQué cierto es! Reconozco esta escena de lenguaje" (1982, p. 5).

Consideraremos aquí discusiones que tienen lugar en foros universitarios -en este caso, un foro de Ciencias Exactas de la UBA y otro de Medicina de la UNR- y construcciones discursivas promovidas por entrevistas en profundidad. 


\section{Foros de discusión}

Los foros de discusión en Internet constituyen recursos virtuales específicos que, lejos de ser un mero "medio" de expresión, configuran modos determinados de sociabilidad, en este caso anclada en la experiencia universitaria. Como aplicaciones web dadoras de soporte a discusiones o intercambio de opiniones en línea, pueden ser pensados desde una perspectiva bajtiniana, como formando parte de géneros discursivos provistos de reglas y lógicas de funcionamiento propias. Más cerca de los géneros primarios que de los secundarios (en tanto el tipo de "conversación" generado es informal) resulta interesante resaltar también el modo en que condicionan la puesta en escena de interacciones discursivas en las cuales las reglas no sólo constituyen un a priori del género sino que en cierta medida se van construyendo in situ (Blanco y Pierella, 2008).

Considerando foros de discusión en los que participan estudiantes universitarios, podemos reconocer en estos una "esfera íntima" o cotidiana inserta en el ámbito universitario más amplio, en la que se generan códigos y discursos que en pocas ocasiones podemos observar en otros espacios de la vida universitaria. Es por esto que los consideramos formas privilegiadas de acceso a la experiencia a través del discurso.

Para el análisis de lo sucedido en estos foros, la utilización del concepto de experiencia (9) habilita una reflexión del fenómeno lejos de las miradas totalizantes que a menudo no permiten pensar la complejidad actual de las instituciones, bajo -por ejemplo- la monolítica idea de "comunidad universitaria" o "comunidad estudiantil" (Ibídem).

En el foro de Exactas son frecuentes los "posts" destinados a intercambiar opiniones acerca de los profesores. Por ejemplo, la conversación iniciada por un estudiante, bajo el título "opiniones sobre profesores" se inicia de este modo: "que opinen sobre los profesores y sus catedras, así los nuevos sabemos más o menos con quién cursar (robé la idea del foro de ingeniería). (Ni7ram). La sucesión de respuestas que desencadena consiste, básicamente en una enumeración de materias y profesores adjetivados con una carga subjetiva en las valoraciones realizadas. Por ejemplo, el nombre de un profesor seguido del siguiente enunciado: "Horripilantemente malo no se anoten con este tipo porque es de cartón corrugado, realmente muy mal profesor. Copia los ejercicios mal, hace los ejercicios mal, parece que no supiera ni lo que está haciendo, habla con re poca seguridad, no pudo demostrar por definición un límite de una variable no porque no le salieran las cuentas si no porque no entendió el concepto de lo que estaba haciendo" (Tytalus). Ante lo cual, quien inicia la conversación, introduciendo regulaciones ad-hoc, responde: "Bien, respuestas como ésas quiero" (Y). Cosas como "fulanito es re buena onda, pero no se entiende mucho cómo explica, a diferencia de pepito que explica mejor, pero no le pone tanta pila así que capaz que te dormís, y es más exigente en los prácticos" (Ni7ram). 
Estamos aquí ante un caso que pone de manifiesto un rasgo propio de la época caracterizado no precisamente por la desaparición de toda autoridad, sino por la proliferación de las mismas. En términos de Bauman, "el capitalismo liviano, amistoso con los consumidores, no abolió las autoridades creadoras de la ley, ni las hizo innecesarias. Simplemente dio existencia y permitió que coexistiera una cantidad tan numerosa de autoridades que ninguna de ellas puede conservar su potestad durante mucho tiempo, y menos aun calificarse de "exclusiva (...) Numerosas autoridades, es, en realidad, una contradicción en los términos. Cuando las autoridades son muchas, tienden a cancelarse entre sí, y la única autoridad efectiva es la de quien debe elegir entre ellas. Una autoridad en potencia se convierte en autoridad por cortesía de quien elige" (Bauman, 2007, p. 70). Así, "las autoridades ya no mandan, intentan congraciarse con los electores por medio de la tentación y la seducción (Bauman, op. cit.). En algún punto, pareciera instalarse una escena de venta de productos en el mercado de servicios pedagógicos, en el que la experiencia de los pares adquiere preponderancia y brinda seguridad frente a lo desconocido y en el que se determinan a priori los atributos del buen docente, de modo tal de presentar el menú que más se adapte a los gustos y necesidades del consumidor: " $X X$ es muy clara. Puede ser algo aburrida, pero tus apuntes quedan como un libro (si eso es lo que te gusta). A mí, me gusta más alguien que de más ideas, peré se que soy de la "minoría". (El Enzo), "XX es aburrida!! Para cursar con XX te tiene que gustar mucho la matemática. No es una profesora que va a intentar "seducirte" (como diría Paenza) con las matemáticas, te va a escupir el temario y listo..." (Daniel-Qco).

En cierto modo, la condición de Internet como realizador privilegiado de la "utopía del medio comunicativo "a la carta", armado de acuerdo con los gustos y las necesidades de cada comensal y definido desde demandas distinguibles de otras" (Urresti, 2008), adquiere resonancia aquí otorgando visibilidad a ciertas manifestaciones de la experiencia.

En el foro de Medicina de la UNR se visibilizan cuestiones similares. En un post titulado "consulta sobre carrera" en el cual quien lo inicia plantea inquietudes en relación con ciertos cursos de cirugía, resulta significativa, desde nuestro recorrido, la frecuencia de intervenciones del siguiente tenor: "Una cosa quiero acotar. Es que cuando te vayas a anotar, tratá de que en lo posible te toque $m$., no me acuerdo bien qué día está pero que te toque ÉL! Te digo porque cuando yo lo hice, allá por 2 do. Año me tocó un paranoico re mala onda que se llamaba $p$. que puede saber un montón y todo lo que quiera pero forreaba bastante "a estos del plan nuevo".(Bahamito).

La autoridad no está aquí dada por la investidura profesoral universitaria, sino que viene precedida de una serie de investigaciones acerca de la figura en cuestión; lo cual, podríamos aventurar, le daría a las experiencias posteriores el carácter de instancias de comprobación o refutación de las hipótesis construidas en el diálogo con otros. 


\section{Entrevistas}

A partir de las entrevistas realizadas (10), es posible destacar en los discursos de los estudiantes, el carácter polisémico de la noción de autoridad. Encontramos sentidos que nos permiten pensar en diferentes "figuras" de autoridad construidas discursivamente, como así también modos de narrar la experiencia que dan cuenta con crudeza de la puesta en cuestión de dichas figuras.

Puede observarse, incluso en el discurso de un mismo estudiante -a través de "esa ambivalencia que distintos autores señalan como rasgo constitutivo de las identidades de las instituciones contemporáneas" (Carli, 2008, p. 21)- posiciones acerca de la autoridad más en clave de obediencia, de dominación, de autoritarismo y otras que se acercan al sentido de autorización y habilitación, de responsabilidad en la operación de transmisión.

La primera de esas claves es narrada utilizando términos como miedo, abandono, sensación de impotencia frente a figuras que son percibidas por los estudiantes como ocupando lugares distantes, lejanos, y destacándose la cuestión de una asimetría que es relatada como inhabilitante en términos no sólo académicos sino subjetivos. Así, son frecuentes las referencias a figuras que utilizan su posición en el campo para marcar diferencias, que desigualan para confirmarse en ese lugar por miedo a perderlo (Greco, 2007): "Pero frente al profesor alguno no podía promocionar la materia, porque la profesora lo obturó, digamos. Es un choque que se da entre fuerzas, el "yo puedo y vos no", "acá la que tiene el poder soy yo y vos vas a escuchar lo que te digo". Si no hay posibilidad de diálogo, de escucha, porque por ahí, la profesora espera escuchar sólo lo que ella quiere, lo que su libro dice... eso no genera nada; ¡o sí! Genera miedo. Genera decir lo que la otra persona quiere que digas" (Estudiante de Trabajo Social).

Relatos que ponen de manifiesto la presencia del poder despojado de autoridad -que tiene todas las oportunidades de aparecer como arbitrario- porque está en directa correlación con atributos de la personalidad (Dubet, 2006).

Por otra parte, se cuestionan las posiciones asimétricas cuando éstas remiten a legitimar principios de desigualdad entre los sujetos; reconociendo, al mismo tiempo, la asimetría y la diferencia necesarias desde el punto de vista de la transmisión de conocimientos. "Un profesor en una cátedra no puede hablar como cualquier hijo de vecino, por eso a $R$. hay que alabarlo, habla cultivadamente (...) Tampoco me gusta esto de que el profesor esté parado y los estudiantes sentados; eso es artificial, es una imposición, frente a chicos de 18... Dalí innovó mirando al Cristo desde arriba... Si fuera profesor daría clases en un bar, en mi casa..." (Estudiante de Letras). "Con otros profesores se genera una cosa simétrica por la personalidad, está la asimetría epistemológica necesaria, y la simetría humana, algunos la generan en el aula" (Estudiante de Ciencias de la Educación).

Se narran situaciones en las que se padecen arbitrariedades de parte de figuras no reconocidas simbólicamente, generadoras, sin embargo, de una 
dependencia y una pasividad inquietantes de parte de los estudiantes, que en ciertos casos no encontraron en la institución instancias de protección frente a lo que enuncian como abusos de poder. En estos casos, la autoridad es de algún modo "desnudada", en el sentido de percibirse los mecanismos originarios de su constitución; es decir, que más allá de ella lo que hay es fuerza de institución y de imposición. Así, podríamos pensar que ciertos actores sociales, por el modo en que ocupan los lugares asignados contribuyen en el proceso de desnaturalización de su autoridad, confirmando que la eficacia de la misma depende de los créditos asignados; más allá de eso, trasponiendo dichos límites, desilusión, escepticismo, e incluso impotencia es lo que adviene (11).

- "Entonces los profesores que juegan con el poquito poder que tienen, lo siguen haciendo. No me parece.

- ¿A qué te referís con "poquito poder"?

- Tampoco es demasiado poder, en ese momento con nosotros, después... Para recibirnos nos sometemos a que hagan lo que quieran. Una falta de respeto, sobre nuestros derechos. No sé si está bien. En algún punto, bueno tampoco te vas a estar peleando con todo el mundo como algunos chicos, tampoco la confrontación todo el tiempo..." (Estudiante de Psicología).

Ante el relato de experiencias como éstas, sobreviene la sensación de que la institución, como institución simbólica, encuentra aquí dificultades para instituir operaciones de reconocimiento subjetivo del otro. También dentro de este tipo de discursos se entrevé la fuerza del encuentro con un otro en el proceso de formación, el modo en que los profesores se constituyen en autoridades en situaciones particulares, en el discurso de sujetos en singular:

"M: A mí me pasó algo parecido a él con alguien que no lo quiere nadie en la facultad, pero yo le tengo un gran aprecio, le sigo hablando, saludando y no la quiere nadie. Yo rendí el final con ella y 10 puntos, me fue guiando.

C: Está bien M., pero no es buena persona, las cosas que le ha hecho a los chicos no tiene nombre..." (Estudiantes de Odontología).

Se establecen diferencias marcadas por los estudiantes en el modo que cada profesor ocupa, "encarna" el lugar que le ha sido asignado, afirmándose que la responsabilidad, el "hacerse cargo" es una de las formas en que se asume la autoridad, como así también se escuchan demandas en torno a que la legitimidad que da el cargo sea respetada:

"Hay profesores a los que no les importaba nada, nos dejaban que nos copiemos. Les importaba cobrar el sueldo e irse, nada más, como hubo otros muy buenos, muy buenos. Saben mucho, tienen mucho conocimiento y exigen por lo que saben ellos.

- Esos que son muy buenos, ¿cómo los definirían?... los que saben mucho. 
- Porque saben y saben cómo llegar al alumno, saben como expresarse. Otros saben mucho, concursan pero no saben cómo hacértelo llegar" (Estudiante de Ciencias Agrarias).

"Otra cosa importante son los concursos de los profesores, no hay tantos concursos. Por ahí dan clases profesores que no sabés si concursaron o no. Eso es bueno para el profesor que tiene el mérito de dar en una facultad pública y para el alumno que está yendo a una clase con un profesor que hizo mérito para eso" (Estudiante de Abogacía).

Adquieren centralidad aquellos elementos de la discursividad que dan cuenta de ciertas "fallas" a nivel de la transmisión, en el sentido de reclamarse referencias autorizadas, vías legítimas que permitan que la transmisión del saber sea posible; institución de posiciones asimétricas que posibiliten el "pasaje" necesario en toda situación de formación.

"Yo creo que eso es un error, mucha gente dejó la facultad por ese miedo, por no entender, imaginate... No sé cómo la columna va con la viga, no sé... A lo mejor era ese profesor, no sé, pero tirame un libro, algo donde ver, él decía "vayan y véanlo". Cuando decía "dibujá un inodoro en un baño. ¿Cuánto mide un baño? Andá y medilo", bueno ahí sí, pero un corte... piso, pared, techo, no sé... ahí recurría a alguien que sabía, a alguien de escuela técnica, a alguien que recursaba para que me lo explique (...) Yo estaba abandonada totalmente" (Estudiante de Arquitectura).

"Llegué a una facultad donde no se dictaban clases, era algo nuevo, un plan nuevo que se estaba probando. Los alumnos tenían que ir a una tutoría una vez por semana, se estudiaban los contenidos solos y en ese momento de las tutorías se podía consultar con un compañero. El tutor podía ser un médico, un enfermero, un psicólogo, o cualquiera (...) Uno podía estar hablando del ADN con un sociólogo" (Estudiante de Medicina).

Por otra parte, se formulan discursos que hacen referencia a las luchas por el poder que, en términos de Bourdieu, tienen lugar en el afán de ganar posiciones dentro del campo universitario. Cabe destacar que este tipo de alusiones fueron más frecuentes en los relatos de estudiantes de carreras más tradicionalmente vinculadas en el espacio social a las posiciones de prestigio otorgadas a nivel profesional por la pertenencia al campo académico, como Medicina, Derecho, Odontología, Arquitectura. Las diferencias epistemológicas, políticas o académicas percibidas entre los profesores son vivenciadas por los estudiantes como perjudiciales en su formación.

“- Entre cátedras de la misma materia no son muy amigables.

- Hay mucha competencia entre sí, yo me di cuenta porque ahora estamos haciendo un proyecto integrado. (...) El profesor quiere que corrijamos sólo con él, no con otros y con él nunca podemos corregir, lo tenemos que buscar, prácticamente. Otro profesor se re preocupó por nosotros y yo creo que le 
dijeron de todo porque nunca más se pudo acercar. La competencia también está entre los profesores.

- A ver cuál es la cátedra multitudinaria" (Estudiantes de Arquitectura).

También se percibe la crisis de ciertas profesiones tradicionalmente prestigiosas, impactando en los mecanismos de la distinción social:

"Hay diferencia entre un cirujano, un traumatólogo y un clínico, lo que gana cada uno se nota en la vestimenta. Los médicos están ganando muy poco, hay médicos muy sencillos. Yo el otro día fui al parque y ivi a uno tomando mate en short!" (Estudiante de Medicina).

Los fragmentos discursivos hasta aquí seleccionados ponen de relieve expresiones que nos permiten hipotetizar que aquello que prima en el tránsito por las diferentes facultades es una clara sensación de desencanto respecto de los profesores, a los que no se les otorgarían los créditos necesarios para ser reconocidos como autoridad.

Sin embargo, cabe destacar que en la totalidad de las entrevistas hay sobradas referencias a la importancia de algunas figuras profesorales en la experiencia universitaria, a la "huella" que deja la misma en las trayectorias educativas e incluso biográficas.

"El único al que me encantaba ir a las clases era el de M., creo que gracias a ése estudié, transmitía ganas de estudiar.

- Lo que tenía era que llevaba mucho a la aplicación te decía "tenés que saber esto, porque sin esto, ¿cómo vas a hacer en la obra?, ¿qué le vas a decir al albañil?" eso te daba ganas de saberlo (...) Las materias prácticas o el tipo que te dice "esto lo vas a necesitar acá, esto es así...", eso está bueno. Te incentiva a ir, cursar, te dan ganas de rendir. Disfrutaba prepararla" (Estudiante de Arquitectura).

Rescatan la presencia de aquellos profesores "abiertos", sorprendiéndose al reconocer gestos de cercanía, de reconocimiento.

"R. es un tipo muy gracioso, lo hace muy llevadero. Muy abierto, acepta al prójimo, la otredad, la acepta, algo bastante vedado; incluso en la famosa facultad del libre albedrío, está muy vedado eso. Son profesores emblemáticos, te dan algo sabiendo mucho de otras cosas. $R$. es muy solidario, me abrió las puertas de su casa" (Estudiante de Letras).

"- El profesor tiene que marcar un límite de jerarquía, no es lo mismo que el alumno, pero a su vez quebrar esa frialdad que provoca el hecho de tener más conocimiento. O sea una relación cómoda yo creo.

- ¿Tuviste ese tipo de relación cómoda en la facultad con algún profesor o profesora?

- Sí.

- ¿Por qué te acordás de ese profesor? 
- Porque cada vez que nos veía en el bar, nos saludaba con un beso a todas. Nosotras no lo podíamos creer, “¿cómo andan?" preguntaba (...) era muy relajado todo. Más allá de exigirnos fue bueno, tengo ese recuerdo" (Estudiante de Administración de Empresas).

Encontramos, a su vez, a la hora de reflexionar sobre las causas del reconocimiento hacia ciertos profesores menciones a:

- La forma de dar clases, de hablar, de "teatralizar".

"Con este tipo vos te encontrabas con algo groso, yo en Arquitectura nunca había tenido un docente así. Un tipo que podés respetar más o menos, pero como dijo él en un seminario "hay una precondición para el aprendizaje, que es que vos le reconozcas una autoridad al tipo que te va a enseñar" (...) Al encontrar a este tipo que era muy bueno, que podía sostener un auditorio cuatro horas y con un nivel de precisión, de detalle y con una complejidad... El tipo lo hacía entendible, era como estar leyendo un texto, era llamativo. Otra cosa... Lo bueno de este tipo como de cualquier buen docente, un buen docente te hace la diferencia en una carrera... en la bibliografía no está la diferencia... Según el modelo de cómo trabaje el tipo uno aprende más, o menos, marca la diferencia. A veces la bibliografía que manejan es la misma, pero la manera de dar clases, cómo trabajen los textos, es lo que hace que uno se entusiasme" (Estudiante de Filosofía).

- La forma de relacionarse con el objeto de conocimiento y con la docencia: "Recuerdo a los profesores que podían transmitir la materia con pasión, eso se nota... con lo metódico, después con la solvencia. ..." (Estudiante de Letras). "Lo que siempre valoré y lo que marca la diferencia entre un profesor y otro es lo que se han calentado por estudiar, esa es la diferencia básica. Yo siempre esperé que si te dedicás a algo sea a morir, eso es lo que ves acá... Tipos que se han dedicado a morir, cuarenta años estudiando, escribiendo, leyendo, investigando. El tipo que es malo te prepara una clase con un texto pero superficial, el otro un tratamiento real. El que te demuestra después de tantos años de laburo a donde ha llegado... ese es, una vida en eso y no la docencia como un laburo más" (Estudiante de Filosofía).

- El reconocimiento de vínculos claros con la autoridad asignada a otras instituciones dadoras de legitimidad, como la institución de la "política", de la "militancia" y que se presentan en estrecha relación con el "contenido" que se transmite o con la "persona" del profesor:

"Esta profesora de la que te hablo genera una cierta ruptura, más allá de las coincidencias ideológicas, hay algunas cuestiones que son tal vez más finas, una cuestión no sólo epistemológico-científica del materialismo, sino de las posibilidades... a ver no recuerdo quién era que hablaba de que el materialismo histórico en el fondo es una teoría del amor, de la igualdad del ser humano, de 
evitar el sufrimiento. Creo que lo que falta es eso, cierto amor por el otro. Ella viene a romper un poco con eso "hay que humanizar las prácticas" (Estudiante de Ciencias de la Educación).

"Los que pasaron por la dictadura y están todavía en pie... la voluntad de seguir..." (Estudiante de Ciencias de la Educación).

- Una reivindicación de la responsabilidad, del "hacerse cargo" en una institución "en crisis":

"M. es una persona con integridad, me acuerdo que una vez a una amiga le dijo del parcial... "en la universidad no hay vacaciones, se estudia" le dijo, es una persona que mantiene lo que dice. El otro día dijo "el parcial es individual, la universidad está decayendo en nivel, pero acá mantenemos el parcial individual, el nivel decae y queremos mantener lo que hay" (...) Yo creo que de mis compañeros y amigos ninguno se va a quejar de ella" (Estudiante de Ciencias de la Educación).

Podemos destacar, de este modo, diferentes formas de reconocimiento de las posiciones autorizadas en los discursos de los estudiantes, lo cual nos permite hablar de ciertas "figuras de autoridad" generadoras de marcas en la subjetividad, vínculos entre "maestros" y "discípulos" que quizás operen como "la cuerda permanente de la vida del conocimiento" (González, 2008, p. 11).

\section{Reflexiones finales}

El proyecto de investigación en el cual este artículo se enmarca se encuentra aun en proceso, razón por la cual las reflexiones aquí expuestas no constituyen conclusiones acabadas. Preliminarmente, podemos afirmar que los discursos rastreados acerca de la autoridad en la Universidad forman parte de ese marco global de lo decible y lo aceptable en una época, dan cuenta de la hegemonía en tanto "conjunto complejo de normas y de imposiciones diversas que operan contra lo aleatorio, lo centrífugo y lo desviante, que indican los temas aceptables e indisociablemente, las maneras tolerables de tratarlos y que instituyen las jerarquías de legitimidades (de valor, de distinción, de prestigio) sobre un fondo de homogeneidad relativa" (Angenot, 1989, p. 8).

Creemos que, en primer lugar, las reglas que organizan lo decible acerca del tema en cuestión se articulan con un fenómeno complejo que caracteriza a las sociedades posmodernas: la complementariedad entre la ausencia o debilitación de un orden simbólico o "código de ficciones aceptado" (Zizek, 1999) con la necesidad de encontrar agentes, entidades, autoridades que ordenen la vida social y subjetiva. Es posible aventurar que el enunciado legítimo que atraviesa las diferentes zonas discursivas abordadas aquí, aquel que está en el centro de la hegemonía, se organiza sobre la exaltación de la figura del individuo como hacedor de su propio destino, lo cual se encuentra estrechamente 
relacionado con fenómenos de declive de una ley organizadora y protectora del sujeto y de los lazos sociales.

El auge de la evaluación del rendimiento como criterio para "medir" el desempeño académico, la liviandad con que se deslegitima a las instituciones de educación superior y el descrédito en las figuras profesorales presentes en buena parte de las entrevistas y foros considerados, se organizan sobre un sistema de reglas relativamente homogéneo; ocupando la noción de "carisma" una posición estelar.

El discurso hegemónico, al mismo tiempo que reconoce el lugar de la educación en la transformación de los sujetos y las sociedades, deja de creer en los agentes a los que tradicionalmente se les asignó dicha función y en la capacidad de la autoridad para habilitar la fundación de lazos sociales relativamente consistentes. Sin embargo, los discursos de los estudiantes entrevistados permiten apreciar al mismo tiempo una línea de fuga respecto de ese discurso incrédulo e inhabilitador; evidenciándose la potencia de las figuras profesorales en los procesos de transmisión cultural entre generaciones.

\section{Notas Bibliográficas}

(1) Hago referencia al proyecto de tesis "Autoridad pedagógica y experiencias estudiantiles. Crisis y perspectivas de los procesos intergeneracionales de transmisión de la cultura en la universidad contemporánea", dirigido por la Dra. Sandra Carli en el marco de dos proyectos colectivos de investigación: CONICET PIP N 5889 "Narrativas de estudiantes universitarios y sus familias sobre la experiencia educativa en el tiempo presente. Transformaciones del sentido de la educación" y UBACYT S003 (2008-2010) "La experiencia universitaria. Estudios sobre la universidad pública".

(2) La crisis de cobertura y la ausencia de calidad fueron los temas principales de la Conferencia Regional de Educación Superior (Cres-2008) realizada entre el 4 y el 6 de Junio en Cartagena de Indias (Colombia) y coordinada por el Instituto Internacional para la Educación Superior en América Latina y el Caribe (lesalc) y el Ministerio de Educación Nacional de Colombia. Diario La Capital, Rosario 12 de junio de 2008. Versión digital.

(3) En términos de Carli, "esta ausencia de perspectiva histórica cristaliza en posiciones conservadoras del atraso, con lecturas míticas respecto de un pasado dorado al que no es posible retornar, o en posiciones abstractas en tanto imaginan una institucionalidad punto cero, fundacional. La perspectiva histórica no debería ceñirse a la meta de recuperar la pequeña o gran historia de la Universidad, atenta a una mirada del pasado lejano o de la historia reciente, sino intervenir también en la lectura del tiempo presente de la Universidad en tanto en éste anidan distintas temporalidades no siempre recuperadas a la hora de pensar la cuestión institucional (intervenciones, reformas, cambios parciales, reorientaciones, etc)" (2008, p. 5). 
(4) También Gramsci, a principios del siglo XX, desde la cárcel de una Italia aquejada por un fascismo cada vez más agudo y de una Europa al borde de la tragedia, hacía referencia a una crisis de autoridad, encontrándola ligada a una "oleada de materialismo" y a la pérdida de consenso de la clase dominante, "que ha dejado de ser "dirigente" y es tan sólo "dominante", detentadora de la pura fuerza coercitiva" (1987, p. 161). Resulta interesante observar en ambos pensadores la asociación entre crisis de autoridad y ascenso de posiciones "autoritarias".

(5) "La doxa es lo que se impone por sí mismo, lo que no convence más que a los convencidos, pero a los convencidos ignorantes de los fundamentos de su creencia; lo que es impersonal, pero sin embargo necesario para poder pensar lo que se piensa y decir lo que se dice. Esta doxa forma un sistema maleable donde un topos puede "esconder otro", de manera que los hacedores de paradojas están atrapados en la doxología de su tiempo" (Angenot, 1989, p. 12).

(6) En un trabajo anterior analizamos el modo en que se fue construyendo, durante los años ' 80 en Argentina, la hegemonía alrededor del término democracia y la irradiación del mismo al ámbito pedagógico, a partir de la consigna amplia de "democratización de las instituciones y de las relaciones pedagógicas". La ilusión redencionista de la transición, acompañada por el significante omnipotente de la democratización, no ocasionó, como muchos se imaginaron, la recuperación de valores alternativos perdidos bajo el horror dictatorial, sino que fue sucedida por el desencanto ante lo público y la enunciación incansable de la "crisis". Las creencias que habían dado forma al cuerpo de profesionales representantes del Estado se debilitaron, en un contexto de transformaciones y ruptura de contratos fundantes que había comenzado en el período previo. La dictadura no sólo hizo que autoridad y autoritarismo se dieran la mano sino que perpetró el quiebre de lo público como marco de referencia para el despliegue de las subjetividades. (Ver Pierella, 2005 y 2006).

(7) Los conceptos de eficiencia y eficacia formaron parte del sentido común de esos años: "La primera hace referencia a la racionalidad y productividad de los procedimientos organizativos, de las acciones y de los procesos educativos; se refiere a la relación que se obtiene entre los resultados de la educación y los recursos dedicados a ésta. La eficacia, por su parte, apunta a la valoración social del producto educativo, en función de los ámbitos culturales, políticos y económicos vigentes" (Chiroleu, 2005, p. 48). Las cursivas pertenecen a la autora.

(8) Max Weber presenta tres tipos de fundamentos para la legitimidad de los diferentes modos de autoridad:

- La legitimidad tradicional, "que descansa en la creencia cotidiana en la santidad de las tradiciones que rigieron desde lejanos tiempos y en la legitimidad de los señalados por la tradición para ejercer la autoridad". 
- La legitimidad fundada en el carisma, "que descansa en la entrega extracotidiana a la santidad, heroísmo o ejemplaridad de una persona y a las ordenaciones por ella creadas o reveladas (...)".

- La legitimidad racional, "que descansa en la creencia en la legalidad de las ordenaciones estatuidas y de los derechos de mando de los llamados por esas ordenaciones a ejercer la autoridad" (1992, p. 172).

Sosteniendo que la inestabilidad es el rasgo central y el principal problema de toda autoridad basada en el carisma, Burton Clark afirma, por un lado, que dicha inestabilidad se reduce cuando el carisma no está exclusivamente vinculado a los individuos, sino a ciertas posiciones sociales específicas y por esta vía a las personas que las ocupan, por otro, que "las situaciones propicias para la aparición de la autoridad personalista son terrenos fértiles para el carisma" (1983, p. 182).

(9) La noción de experiencia ha sido visitada, incluso de modo abusivo, por las reflexiones pedagógicas y de crítica cultural en general, para llamar la atención, siguiendo a Benjamin, sobre su "muerte" o "destrucción", enfatizando en la ausencia de experiencia en el mundo contemporáneo, en estrecha relación con el ocaso de la figura del narrador (Benjamin, 1991). Nuestra intención es retomar el carácter positivo de la experiencia benjaminiana, en tanto filosofía vuelta en acción de comunicar nuevos sentidos de lenguaje capaces de incidir sobre la realidad, y en tanto integrada en la formación social en que el sujeto se inscribe (Verón Ospina, 2001).

En este sentido, recogiendo la herencia del programa de Benjamin, Agamben advierte, oportunamente, acerca de no deplorar la realidad de "desaparición de la experiencia, sino de tenerla en cuenta. "Ya que tal vez en el fondo de ese rechazo en apariencia demente se esconda un germen de sabiduría donde podamos adivinar la semilla en hibernación de una experiencia futura" (Agamben, 2007, p. 10). Quizás gran parte del malestar universitario actual radique en la dificultad de poder encontrar o nombrar las nuevas experiencias en el presente.

(10) Se realizaron hasta el momento 18 entrevistas a estudiantes próximos a egresar, abarcando la totalidad de facultades de la UNR. 12 entrevistas individuales y 6 grupales. Omitimos los nombres de los entrevistados para preservar su identidad.

(11) Dice en este sentido Derrida: "Hay un silencio encerrado en la estructura violenta del acto fundador. Encerrado, emparedado, porque este silencio no es exterior al lenguaje. He ahí el sentido en el que yo me atrevería a interpretar (...) lo que Montaigne y Pascal llaman el fundamento místico de la autoridad (...) Dado que en definitiva el origen de la autoridad, la fundación o el fundamento, la posición de la ley, sólo pueden, por definición, apoyarse en ellos mismos, éstos constituyen en sí mismos una violencia sin fundamento. Lo que no quiere decir que sean injustos en sí, en el sentido de 'ilegales' o 'ilegítimos'” (1994, pp. 33-34). 


\section{Referencias Bibliográficas}

- $\quad$ Agamben, G. (2007) Infancia e historia. Buenos Aires, Adriana Hidalgo.

- $\quad$ Angenot, M. (1989) Un ètat du discours social. Le Préambule. Québec. Chapitre 1. Traducción realizada por Alejandro Gay y Weller, G. para la Maestría en Sociosemiótica del C.E.A. (revisión de Ma. Teresa Dalmasso). sobre las periferias del Discurso Social en 1889", en Interdiscursividades. De hegemonías y disidencias. Universidad Nacional de Córdoba.

- Antelo, E. (2003) "Lo que queda del maestro", en Lo que queda de la escuela. Cuadernos de Pedagogía. Rosario, Laborde.

- $\quad$ Arendt, H. (1996) Entre el pasado y el presente. Barcelona, Península.

- Barthes, R. (1982) Fragmentos de un discurso amoroso. México, Siglo Veintiuno.

- Bauman, Z. (2005) Modernidad líquida. Fondo de Cultura Económica, Bs.As.

- Blanco, R. y Pierella, M. (2008) "Experiencias estudiantiles en la Universidad contemporánea. Una aproximación a los discursos acerca de la autoridad y la sexualidad en foros de discusión". Ponencia presentada en las XII Jornadas Nacionales de Investigadores en Comunicación. "Nuevos escenarios y lenguajes convergentes". Facultad de Ciencias Políticas y Relaciones Internacionales, Rosario, 16, 17 y 18 de octubre de 2008. Versión digital: http://www.redcomunicacion.org/memorias/pdf/2008Blponencia\%20blanco-pierella\%20ok.pdf.

- Bourdieu, P. (2008) Homo Academicus. Buenos Aires, Siglo Veintiuno.

- Carli, S. (2001) "Discontinuidad e historización. Una mirada sobre la relación entre adultos y jóvenes en la Argentina contemporánea", en Revista Ensayos y Experiencias, Año 8, $N^{\circ}$ 40, Sept/Oct.

(2008) "Visiones sobre la Universidad pública en las narrativas estudiantiles. La experiencia universitaria entre la desacralización y la sensibilidad", en Revista IICE N² 26, Facultad de Filosofía y Letras - UBA.

- Clark, B. (1983) El sistema de educación superior. Una visión comparativa de la organización académica. México, Nueva Imagen/Universidad Autónoma Metropolitana.

- Cornu, L. (2005) "Transmisión e institución del sujeto. Transmisión simbólica, sucesión, finitud", en Frigerio, G. y Diker, G. (Comps.) La transmisión en las sociedades, las instituciones y los sujetos. Un concepto de la educación en acción. Buenos Aires, Noveduc/Cem.

- Chiroleu, A. (2005) "La educación superior en la agenda de gobierno argentina en veinte años de democracia (1983-2003)", en Rinesi, E., Soprano, G. y Suasnábar, C. (Comps.) Universidad: reformas y desafíos. Dilemas de la educación superior en la Argentina y el Brasil. Buenos Aires, Prometeo/Universidad Nacional de Gral. Sarmiento.

- Dalmasso, M. (2005) "Semiótica y análisis crítico del discurso social", en Actas del VI Congreso de la AAS - Discursos críticos, Buenos Aires. 
- De Certeau, M. (1995) Historia y psicoanálisis. México, Universidad Iberomericana.

- Derrida, J. (1994) Fuerza de ley. El fundamento místico de la autoridad. Madrid, Tecnos.

(2002) Universidad sin condición. Madrid, Minima Trotta.

- Dubet, F. (2006) El declive de la institución. Profesiones, sujetos e individuos en la Modernidad. Barcelona, Gedisa.

- Dubet, F. y Martuccelli, D. (1998) En la escuela. Sociología de la experiencia escolar. Barcelona, Losada.

- Duschatzky, S. y Corea, C. (2002) Chicos en banda. Los caminos de la subjetividad en el declive de las instituciones. Buenos Aires, Paidós.

- Dussel, I. y Caruso, M. (1999) La invención del aula. Buenos Aires, Santillana.

- Follari, R. (2008) La selva académica. Los silenciados laberintos de los intelectuales en la universidad. Rosario, Homo Sapiens.

- García Guadilla, C. (2002) Tensiones y transiciones. Educación Superior latinoamericana en los albores del tercer milenio. Caracas, Nueva Sociedad.

- González, H. (2008) Prólogo a Duschatzky, L. Una cita con los maestros. Los enigmas del encuentro con discípulos y aprendices. Buenos Aires, Miño y Dávila.

- Gramsci, A. (1987) La alternativa pedagógica. México, Fontamara.

- Greco, M. (2007) La autoridad (pedagógica) en cuestión. Una crítica al concepto de autoridad en tiempos de transformación. Rosario, Homo Sapiens.

- Krotsch, P. y Suasnábar, C. (2002) "Los estudios sobre la Educación Superior: una reflexión en torno a la existencia y posibilidad de construcción de un campo", en Pensamiento Universitario Año 10 № 10.

- Marquina, M. (2007) "El conflicto de la profesión académcia: entre la autonomía, la burocratización y la mercantilización", en Rinesi, E. y Soprano, G. (Comps.) Facultades alteradas. Actualidad de El conflicto de las facultades, de Immanuel Kant. Buenos Aires, UNSAM/Prometeo.

- Mollis, M. (2001) La universidad argentina en tránsito. Ensayo para jóvenes y no tan jóvenes. Buenos Aires, Fondo de Cultura Económica.

- Neave, G. (2001) Educación superior: historia y política. Estudios comparativos sobre la universidad contemporánea. Barcelona, Gedisa.

- Naishtat, F. (2004) "Las dimensiones democráticas de la Universidad y sus razones", en Delamata, G. (Ed.) La Universidad argentina en el cambio de siglo. Buenos Aires, Jorge Baustino/UNSAM.

- Pérez Lindo, A. (2001) "Fundamentos de la Universidad en una era sin fundamentos", en Naishtat, F., García Raggio, A. y Villavicencio, S. (Comps.) Filosofías de la Universidad y conflicto de racionalidades. Buenos Aires, Colihue.

- Pierella, M. (2005) Tesis de Maestría: Autoridad docente, creencia y representación. Una mirada desde la transición democrática: 1983-1989. Maestría en Educación de la Facultad de Ciencias de la Educación de la Universidad Nacional de Entre Ríos. 
(2006) "Infancia y autoridad en el discurso pedagógico postdictatorial", en Carli, S. (Comp.) La cuestión de la infancia. Entre la escuela, la calle y el Shopping. Buenos Aires, Paidós.

- Ricoeur, P. (2006) Caminos del reconocimiento. Tres estudios. México, Fondo de Cultura Económica.

- Sarlo, B. (1998) La máquina cultural. Buenos Aires, Ariel.

- (2001) Tiempo presente. Buenos Aires, Siglo XXI.

- Sennett, R. (1982) La autoridad. Madrid, Alianza.

- - (2000) La corrosión del carácter. Las consecuencias personales del trabajo en el nuevo capitalismo. Barcelona, Anagrama.

- Theodoropoulou, A. (2001) ¿Produce la Universidad un saber crítico? De la crítica de la Academia a la crítica en la Academia, en Naishtat y otros (op.cit.).

- Tiramonti, G. (Comp.) (2004) La trama de la desigualdad educativa. Mutaciones recientes en la escuela media. Buenos Aires, Manantial.

- Urresti, M. (Ed.) (2008) Ciberculturas juveniles. Buenos Aires, La Crujía.

- Verón Ospina, A. (2001) "Algunos apuntes acerca de la construcción de lo heroico en Walter Benjamin”, en Revista de Ciencias Humanas $N^{\circ} 20$, Colombia. http://www.utp.edu.co/ chumanas/revistas/revistas/rev20/index.htm.

- Weber, M. (1992) Economía y sociedad. México, Fondo de Cultura Económica.

- Zizek, S. (1999) ¡Tú puedes!, en http://www.infoamerica.org/documentos_pdf/ zizek02.pdf. (2001) “El espinoso sujeto”. Buenos Aires, Paidós. 